\title{
Population-based study on the incidence of alcohol consumption in pregnancy in easter pommerania: The SNiP birth cohort.
}

A. Lange1, L. Fröhlke2, T. Ittermann3, R. Thyrian3, M. Heckmann1

\section{Introduction}

The incidence of the entire spectrum of alcohol associated disease in newborns is 4-6/1000 births. The potentially avoidable sequelae are of social, medical and socioeconomic relevance.

\section{Methods}

Alcohol consumption in pregnancy was investigated in 5402 pregnant women between 2002-2008 as part of the population-based Survey of Neonates in Pommerania (SNiP). The women filled in an anonymous questionnaire (AUDIT-C, incl. index of dependence). Neonatal outcome parameters were recorded: size, weight, head circumference, APGAR and possible symptoms of a fetal alcohol syndrome (FAS) like stigmata, muscular hypotonia and being small for gestational age. Statistical analysis was performed using SPSS and Stata-Statistic.

\begin{tabular}{lll} 
Education level & $\begin{array}{l}\text { No alcohol } \\
\mathrm{N}=3530\end{array}$ & $\begin{array}{l}\text { alcohol } \\
\mathrm{N}=1040\end{array}$ \\
\hline No education & $66(1.9 \%)$ & $13(1.25 \%)$ \\
$\begin{array}{l}<10 \text { years of } \\
\text { school }\end{array}$ & $2400(68.1 \%)$ & $576(55.4 \%)$ \\
$>10$ years of school & $1017(28.8 \%)$ & $438(42.1 \%)$ \\
$\begin{array}{l}\text { School for special } \\
\text { education }\end{array}$ & $8(0.2 \%)$ & $1(0.09 \%)$
\end{tabular}

Table 2: Education level of the mother and alcohol consumption during pregnancy. Missing data $\mathrm{N}=87(1.9 \%)$

\begin{tabular}{lll} 
& Symptomes of FAS & Preterm delivery \\
\hline OR (Cl 95\%): alcohol/ no alcohol & $1.21[0.84 ; 1.75]$ & $1.42[1.14 ; 1.78]$ \\
\hline OR (Cl 95\%): no information /no alcohol & $1.61[1.07 ; 2.44]$ & $0.71[0.56 ; 0.89]$
\end{tabular}

Table 3: Odds ratios for preterm delivery ( $<37 \mathrm{wks}$ ) and possible symptoms of FAS in women with alcohol vs. without alcohol consumption in pregnancy and women who did not answer the questionnaire vs. those without alcohol consumption.

\section{Conclusions}

In our cohort study, we were able to encourage nearly $90 \%$ of mothers to give detailed information on alcohol consumption in pregnancy.

Although more than $20 \%$ of the questioned women had a regular alcohol consumption, the drinking quantity was low. This may explain the lack of association of alcohol consumption and possible symptoms of FAS.

However, alcohol consumption in pregnancy was associated with higher school education and higher risk of premature delivery. This is of particular importance with respect to preventive measures.

In the small group of mothers who did not fill in the questionnaire, an association between alcohol consumption and possible symptoms of FAS was found. These women should be regarded as a group at risk. Therefore, follow up of their offspring is extremely important.

\section{Results}

4785 (88.6\%) questionnaires were completed.

1077 mothers (22.5\%) stated alcohol consumption in pregnancy. (Table 1)

Of these,

$\mathrm{N}=176$ (16.4\%) drank alcohol on average once a month, $\mathrm{N}=36(3.3 \%) 2$ to 4 times per month, and

$\mathrm{N}=3(0.2 \%) 2$ to 3 times per week.

$54 \%$ of pregnant women with alcohol consumption $>2$ times per month passed the final secondary school examination. (Table 2 )

Mothers with alcohol consumption in pregnancy were more likely to deliver prematurely (<37 weeks of gestation). (Table 3)

Mothers who did not fill in the questionnaire were less likely to deliver prematurely but possible symptoms of FAS were found in their offspring (Table 3).

Diagnosis FAS out of the medical report

- 1 child full screen FAS (0,19/1000 deliveries)

- 3 children with symptoms of FASD $(0,76 / 1000$ deliveries).

Evaluated incidence from 0,63-0,95/ 1000 deliveries

Information on mothers: They have been between 20 and 24 years.

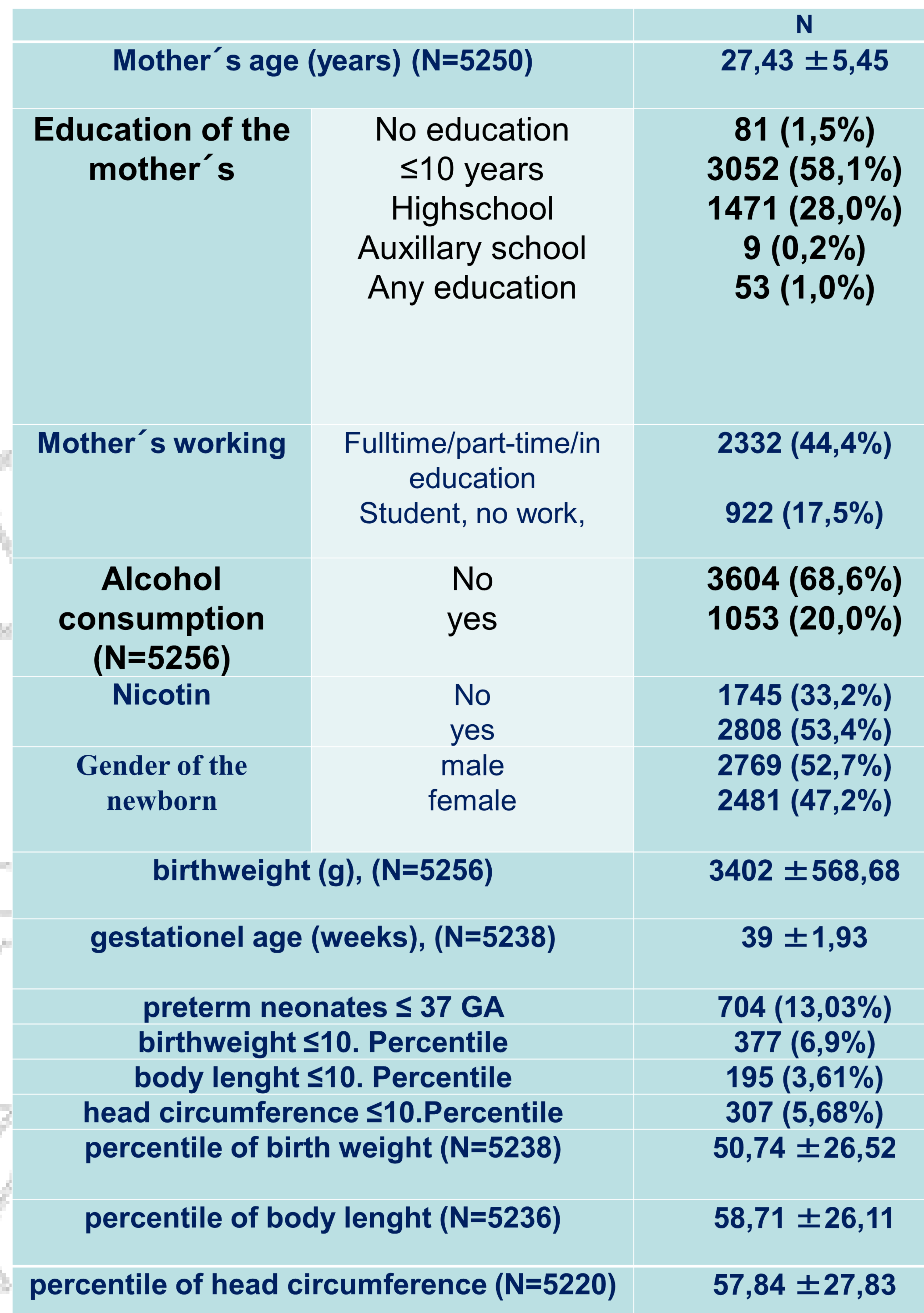

- Table 1: Selected parameters of the study population - Data are given in absolut and relative numbers or mean $\pm S D$ 